\title{
Southern African Office of Astronomy for Development: A New Hub for Astronomy for Development
}

\author{
Moola S. Mutondo ${ }^{1}$ and Prospery Simpemba ${ }^{2}$ \\ ${ }^{1}$ Department of Biological Science, The Copperbelt University, \\ P.O. Box 21692, Kitwe, Zambia \\ email: moola.mutondo@cbu.ac.zm \\ ${ }^{2}$ Department of Physics, The Copperbelt University, \\ P.O. Box 21692 Kitwe, Zambia \\ email: prospery.simpemba@cbu.ac.zm
}

\begin{abstract}
A new Astronomy for Development hub needs innovative tools and programs. SAROAD is developing exciting tools integrating Raspberry Pi technology to bring cost-effective astronomy content to learning centres. SAROAD would also like to report achievements in realizing the IAU's strategic plan. In order to manage, evaluate and coordinate regional IAU (International Astronomical Union) capacity building programmes, including the recruitment and mobilization of volunteers, SAROAD has built an intranet that is accessible to regional members upon request. Using this resource, regional members can see and participate in regional activities. SAROAD has commenced with projects in the three Task Force areas of Universities and Research, Children and Schools and Public Outreach. Under the three Task Force areas, a total of seven projects have commenced in Zambia (some supported by funds from IAU Annual Call for proposals).
\end{abstract}

Keywords. General

\section{Introduction}

In January 2008, the IAU started developing a strategic plan for the decade entitled "Astronomy for the Developing World". This plan aimed to use astronomy in stimulating development at all levels, such as education, research and public outreach. A central coordinating "Office of Astronomy for Development" (OAD), hosted in South Africa at the South African Astronomical Observatory (SAAO) was created as a step towards implementation. In August 2012, at the General Assembly in Beijing, an updated version of the strategic plan was released including an updated title, "Astronomy for Development".

Table 1. Overview of SAROAD Current and Future Members

\begin{tabular}{|c|c|c|c|c|}
\hline | Current Members & Need & Representation & |LOAD/SAROAD Members & SKA \\
\hline | Zambia & | & Swaziland & Angola & Ghana \\
\hline Namibia & | & Seychelles & Mozambique & | Kenya \\
\hline | Botswana & | & Lesotho & | & \\
\hline South Africa & 1 & Congo DR & 1 & \\
\hline Mauritius & 1 & Malawi & 1 & \\
\hline Zimbabwe & 1 & & 1 & \\
\hline Madagascar & | & & | & \\
\hline
\end{tabular}




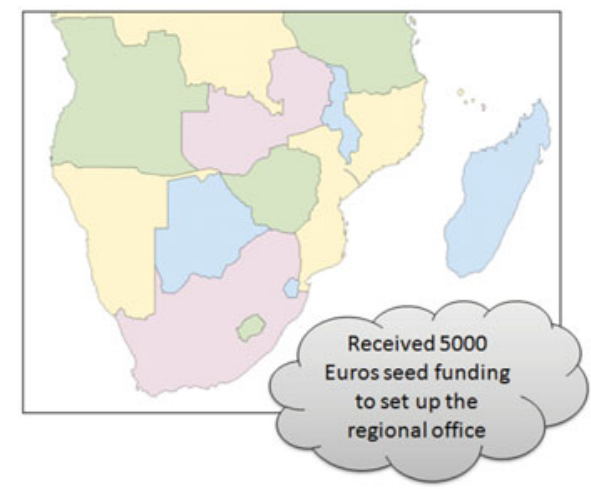

Figure 1. SAROAD Region and Member Countries.

Table 2. Connecting the Astronomy Community in SAROAD Countries

\begin{tabular}{|l|l|}
\hline Providing information: INTRANET & Connecting the Community: Website \\
\hline http://southernafrica.astro4dev.org/ & http://sites.google.com/saroadoffice \\
\hline
\end{tabular}

Table 3. Some Projects under Task Forces

\begin{tabular}{|l|c|c|}
\hline Task Force: Children/Schools & Task Force: Universities / Research & $\begin{array}{c}\text { Task Force: Public } \\
\text { Outreach }\end{array}$ \\
\hline Raspberry Pi Project for schools & Astrolab project (2013-2014)cont. & Solar Astronomy \\
\hline Science Opera (IYL) & Visiting expert Prof. J. Murphy & SAROAD Road show \\
\hline & Traditional Astronomical Knowledge & \\
\hline
\end{tabular}

\section{SAROAD hosted at the Copperbelt University (CBU), Zambia}

The CBU and the IAU signed an important agreement to host a Southern African regional node of the IAU Office of Astronomy for Development on 8th August 2014. This is the second regional node to be established on the African continent and is an important part of the IAU's decadal strategic plan for astronomy to benefit society. The Governance of SAROAD rests on direction from the Steering committee[F. Tailoka: Chairman (CBU); K. Govender (OAD); P. Whitelock (SAAO); H. Mweene (UNZA); M. Backes (UNAM); L. Tonga (MSEVTEE, Zambia); T. Nemaungani (SKA)]. SAROAD spans the African Southern sub-region (Fig. 1) including the countries presented in Table 1 .

\section{SAROAD Activities and Future Outlook}

SAROAD has been active for a year and has achieved the results outlined in Table 2 and Table 3. SAROAD needs to work hard to support astronomy at all levels: amateur, professional and outreach. It is now imperative to build on the current good will expressed across the region concerning Astronomy for Development. SAROAD needs to increase and establish strong support offices at the country level in order to achieve its mandate of facilitating Astronomy to contribute to national and regional development. 